UNEDITED VERSION. The final version is to appear in Energy and Environment, 2009

\title{
Global Warming and Carbon-Negative Technology: Prospects for a Lower-Cost Route to a Lower-Risk Atmosphere
}

\author{
Peter M. Eisenberger ${ }^{1,6} *$, Roger W. Cohen ${ }^{2,6 *}$, Graciela Chichilnisky ${ }^{3,6}$, \\ Nicholas M. Eisenberger ${ }^{4,6}$, Ronald R. Chance ${ }^{5,6}$, and Christopher W. Jones ${ }^{5}$
}

${ }^{1}$ Department of Earth and Environmental Sciences, 109 Geoscience, Lamont-Doherty Earth Observatory, Columbia University, Palisades NY 10964; ${ }^{2}$ P.O. Box 2042, Durango, CO 81302;

${ }^{3}$ Department of Economics and Department of Statistics, Columbia University, 420 West $118^{\text {th }}$ Street, New York, NY 10027; ${ }^{4}$ GreenOrder Inc., 205 Lexington Avenue, New York, NY, 10016; ${ }^{5}$ School of Chemical \& Biomolecular Engineering, Georgia Institute of Technology, Atlanta GA 30332; ${ }^{6} \mathrm{Global}$ Thermostat LLC, New York, NY

* To whom correspondence should be addressed. Email: peter.eisenberger@gmail.com; rogerwcohen@comcast.net

\section{Abstract}

Aggressive efficiency improvements and a shift away from fossil fuels cannot offset climate change threats. This realization creates an imperative for 'carbon-negative' mitigation measures; that is, measures that can reduce atmospheric carbon faster than emissions will load the atmosphere. Among such measures, air extraction technology, coupled with secure sequestration, offers advantages of centralization and control without direct intervention in the biosphere or major collateral environmental impact. Significant new scientific developments in air extraction show promise of greatly reduced costs, such that decreasing the concentration of carbon in the atmosphere to substantailly lower risk levels may be economically practicable. These developments create a strong case for expanded R\&D efforts aimed at advancing air extraction technology.

\section{Introduction}

The Intergovernmental Panel on Climate Change (IPCC) Special Report on Emissions Scenarios (SRES) [1] and other proposed pathways [2-3] to stabilizing the atmosphere at approximately $550 \mathrm{ppm}$ (twice the pre-industrial level) generally do not include mitigation measures based on removing carbon dioxide $\left(\mathrm{CO}_{2}\right)$ from the atmosphere or offsetting the climatic effects of greenhouse gases. Instead, these scenarios rely on shifts to renewable energy sources, future technology efficiency gains, fuel switching, conservation, and land use changes to achieve atmospheric stability. On the other hand, carbon-negative solutions via geoengineering [4-7] or extraction of $\mathrm{CO}_{2}$ directly from the atmosphere [8-12] have been presumed to be technically infeasible, too costly, or to carry the risk of significant collateral environmental impact.

However, a number of recent developments call into question the likelihood of stabilizing the atmosphere at twice the preindustrial level or less without deploying some form of carbonnegative technology. First, emissions continue to increase, perhaps accelerate [13-16]. The increase is driven largely by rapidly developing Asian economies, but even Kyoto signees are 
largely off track in meeting their 2012 emissions targets. Global emissions have already exceeded the flat-line level used by Pacala and Socolow [3], and projections for 2010 and 2015 show increases relative to 2004 of $19 \%$ and 31\%, respectively [15]. Second, an analysis by Pielke et al. [17] has shown that two-thirds or more of the energy efficiency improvements and decarbonization of energy supply required to stabilize greenhouse gases in IPCC scenarios is assumed to arise from spontaneous technological developments and their resulting decarbonization. These assumptions are judged by the authors as optimistic and may significantly underestimate the technological challenge and economic cost associated with achieving atmospheric stability. Third, gaps and differing priorities between industrialized countries, rapidly developing nations (e.g., China and India), and transitioning economies (e.g., sub-Saharan Africa) have emerged as key obstacles to a comprehensive international agreement. The control of emissions by developing economies has become critical to an international solution.

A fourth development raises questions about whether a $550 \mathrm{ppm}$ atmosphere, even if achieved, represents an acceptable climate risk. Roe and Baker [18] argue that scientific uncertainties in the response of the earth's climate to increased atmospheric $\mathrm{CO}_{2}$ may be significantly larger than previously believed, with a bias toward larger responses at a given level of atmospheric greenhouse gases. The authors suggest that these uncertainties are not likely to be reduced appreciably by future research. This development increases the risk associated with future $\mathrm{CO}_{2}$ emissions and implies a risk-reduction premium on measures to stabilize the atmosphere at $\mathrm{CO}_{2}$ concentrations lower than twice the preindustrial level.

Therefore, it appears increasingly evident that a low-risk level of atmospheric $\mathrm{CO}_{2}$ cannot be realized without a significant carbon-negative mitigation component. Furthermore, studies using integrated assessment models $[19,20]$ have found that as yet unspecified future carbon-negative measures may be the most economically effective path to specific atmospheric or climate targets.

We discuss here a possible approach to achieve a global scale carbon-negative solution via low-cost, efficient air extraction technology. The potential role of air extraction in reducing future emissions has been considered by Keith et al. [21] and by Pielke [22]. Here, we show that deployment of technology based on recent scientific developments could prevent atmospheric levels of $\mathrm{CO}_{2}$ from exceeding $450 \mathrm{ppm}$ and return them to current levels by 2100. The key features of the technology are: (1) its utilization of widely-available low-grade process heat to power an adsorption-regeneration cycle, thereby greatly reducing the energy costs of carbon capture; and (2) the efficient harnessing of this process heat, enabling large capture capacities at centralized extraction facilities.

\section{Reference scenarios}

To explore the impact of carbon-negative solutions, we employ as reference cases two scenarios from the IPCC Special Report on Emissions Scenarios of 2000 [1]. We use the scenarios to define a range of futures preserving robust economic growth, while transitioning to a far less fossil-fuel-intensive energy portfolio. The two scenarios are members of the 'A1' family and differ mainly in the degree and speed of a future energy transition [23]. They describe a century of strong economic growth, along with rapid development and diffusion of 
technology-based efficiencies: energy intensity declines at a strong 1.3\% per year over the century. Economic progess is particularly strong throughout the developing world, leading to a much more uniform level of material well being and health across the globe. Clearly, the scenarios represent an optimistic view of future human progress.

Economic progress is accompanied by a move away from fossil-fuel-intensive energy production. The two scenarios bracket the range from an energy portfolio balanced among fossil fuels, renewables and nuclear energy (scenario A1B) to an aggressive adaptation of renewable energy (scenario A1T). The A1T scenario is among the most optimistic (lowest emissions) of all SRES scenarios and the most optimistic of those that maintain strong economic growth in a globalized world [2]. Scenario A1B can be viewed as simply a somewhat less aggressive energy transition. Therefore, the two scenarios represent relatively optimistic views of progress toward broad economic well being in the $21^{\text {st }}$ century and a simultaneous shift toward efficient emissionless energy. At the same time, they do not include strong carbon-negative mitigation measures.

Fossil fuel emission profiles for the two scenarios are shown in the Figure 1. The region between the emissions profiles for the two scenarios can be viewed as a 'domain of optimism.' Within the domain, $\mathrm{CO}_{2}$ emissions peak around the middle of the century and decline thereafter as the transition from fossil fuel resources, along with continued efficiency increases, more than compensates for increased economic growth.

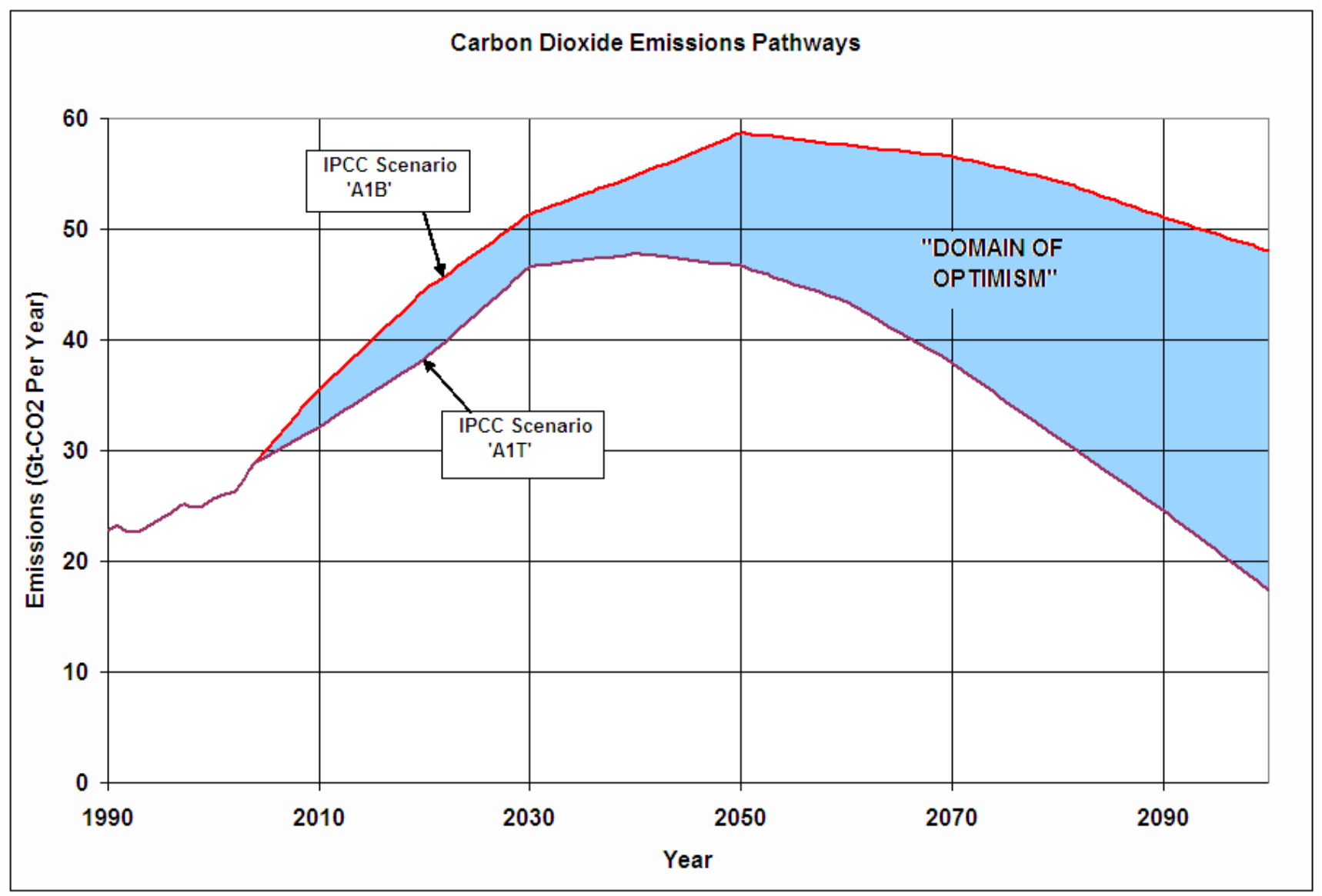


Figure 1. Carbon dioxide emissions pathways to 2100 for the A1B and A1T scenarios. The region between the curves is labeled the "Domain of Optimism," because it represents what could be achieved by future technology efficiency gains and a substantial shift to emissionless energy, while maintaining strong worldwide economic growth. Within the domain, emissions peak around the middle of the century and decline thereafter. (The emissions scenarios shown in the figure have been adjusted slightly upward from the SRES values [1] in order to achieve consistency with the actual emissions history since 2000).

Levels of atmospheric $\mathrm{CO}_{2}$ corresponding to the emissions 'domain of optimism,' as calculated by a carbon cycle model [24] are shown in Figure 2. The key feature of the curves is that, despite the optimistic nature of the scenarios with their emissions peaks in the middle of the century, atmospheric $\mathrm{CO}_{2}$ increases throughout the century and continues into the next. Ultimately, $\mathrm{CO}_{2}$ levels exceed $550 \mathrm{ppm}$, twice the level of $19^{\text {th }}$ century pre-industrial Earth and more than $40 \%$ higher than today's abundance.

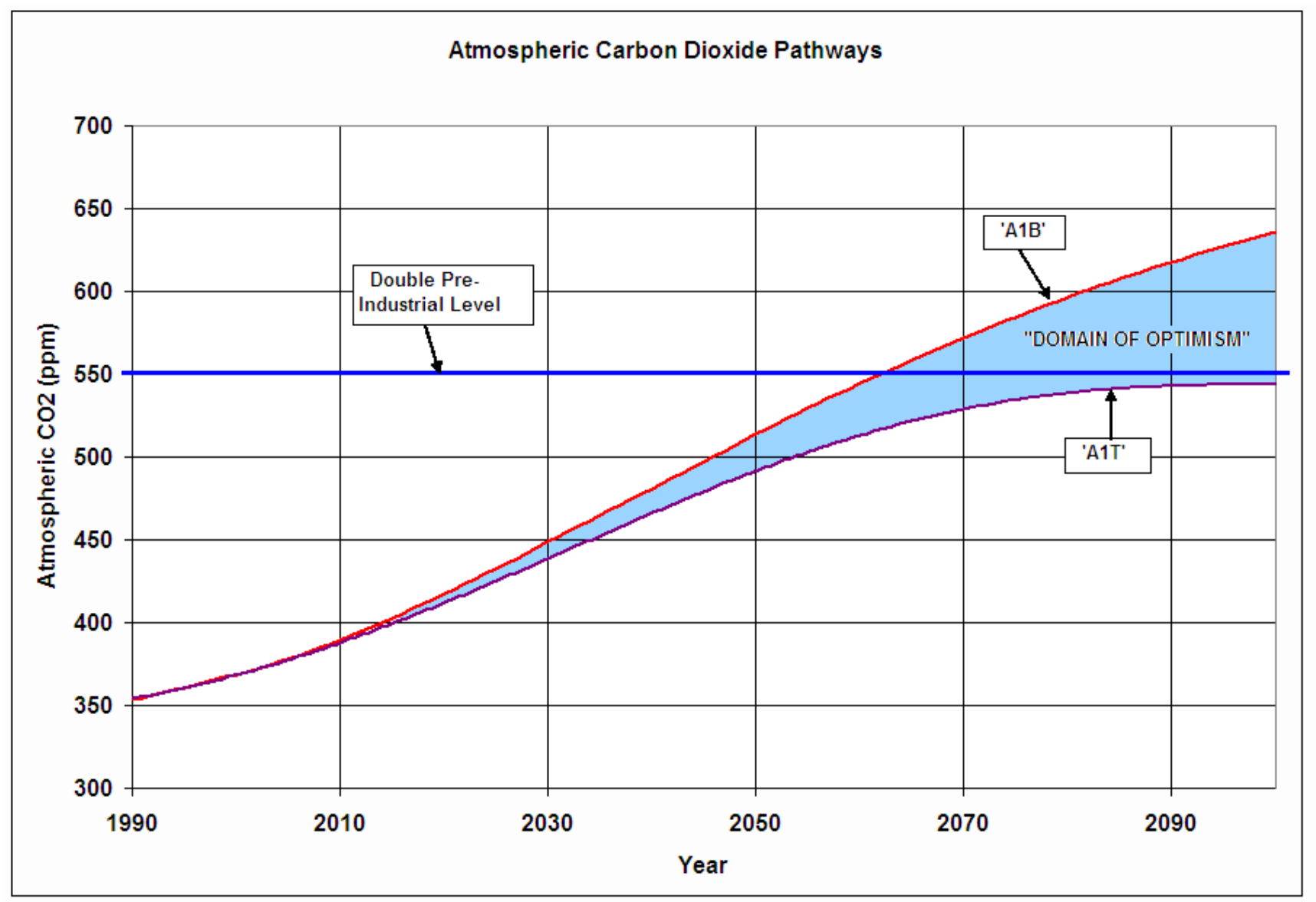

Figure 2. Atmospheric carbon dioxide levels to 2100 corresponding to the emissions scenarios of Figure 1. Atmospheric carbon dioxide eventually exceeds 550 parts per million, twice the estimated pre-industrial level.

Figure 2 demonstrates that even optimistic IPCC scenarios do not prevent atmospheric $\mathrm{CO}_{2}$ from exceeding twice the pre-industrial level. This result is largely due to the decades-long time to achieve peak global emissions, which can in turn be traced to the large capital investments required to effect a major transition to emissionless energy sources. Hoffert et al. [25, 26] and Wigley et al. [27] estimated that by 2050, 10-30 trillion watts of new emissionless primary energy production would be needed to stabilize the atmosphere at 550 
ppm, depending on the future rate of decrease of energy intensity. With current renewables technology costing $\sim$ \$5-10 per installed average watt, the capital requirements could easily exceed $\$ 50$ trillion over 40 years. Such a capital investment would be comparable to the entire current U.S. private fixed nonresidential investment over this period [28]. The relatively long time to effect a major energy infrastructure change is consistent with the findings of Ausubel et al. [29,30], who showed that major infrastructure changes have historically required several decades due to capital and technology requirements.

Therefore, a world future featuring vigorous economic growth, while shifting aggressively away from a fossil-fuel-intensive economy, still presents a significant risk of climate change. These uncertainties warrant consideration of risk-reduction measures beyond the efficiency advances and transition to emissionless energy envisioned in the scenarios and represented by the 'domain of optimism' in the Figures 1 and 2. We define 'carbon-negative' as those measures that can reduce atmospheric $\mathrm{CO}_{2}$. We conclude that such measures are needed to reduce the risk of climate change, even in optimistic scenarios.

\section{Toward a lower-risk atmosphere with a carbon-negative solution from lower-cost air extraction}

Measures to realize a carbon-negative solution fall into two catagories: technology for centralized air extraction of $\mathrm{CO}_{2}$ [8-12] and a variety of geoengineering schemes [4-7]. Geoengineering can involve $\mathrm{CO}_{2}$ extraction via ocean fertilization, forest sequestration, bioenergy with carbon storage (BECS), or other biosphere intervention, or offset of greenhousegas-induced climate change through manipulation of solar radiation reaching the surface and lower troposphere. Examples of the latter include atmospheric aerosols and space-borne reflectors. All proposed carbon-negative measures have costs, issues, and uncertainties that must be weighed against their potential to achieve a safe atmosphere. Proposed geoengineering measures have the potential to ameliorate the effect of $\mathrm{CO}_{2}$ and other greenhouse gas emissions, but their inherent diffuseness and lack of direct control increase the risk of large collateral environmental and ecological consequences. Some measures also pose significant land use and carbon-retention issues. On the other hand, air extraction offers the ability to centralize and control $\mathrm{CO}_{2}$ removal activities without direct intervention in the biosphere and with relatively modest land-use demands. This centralization and control also implies that process economics can be more precisely defined and incorporated in longterm implementation strategies. However, centralized $\mathrm{CO}_{2}$ extraction also implies the need to provide sequestration integrity and stability [31].

To demonstrate the potential impact of a carbon-negative solution on the scenarios discussed above, we will employ the example of air extraction because of the desirable features described above. Furthermore, recent scientific developments demonstrate the potential for substantially reduced costs. Previous embodiments of $\mathrm{CO}_{2}$ extraction technology, whether air extraction or flue gas capture, have required large amounts of valuable high-grade heat to power a temperature-swing-adsorption (TSA) process. This requirement results in large energy costs. For the example of flue gas capture in a new pulverized-coal power plant context, a recent NETL-DOE study [32] finds that the parasitic load introduced by aqueous-amine-based carbon capture increases the cost of electricity by $84 \%$, with a large part of that increase arising from the energy requirements of sorbent 
regeneration. In addition, the dilute $\mathrm{CO}_{2}$ concentration associated with air extraction has been judged a substantial stumbling block [33]. However, new concepts utilizing moistureassisted desorption [11] to recover adsorbed $\mathrm{CO}_{2}$ at relatively low temperatures or tailored immobilized amine sorbents [12, 34-37] have the potential to greatly reduce extraction costs by employing only low-grade process heat. Furthermore, by avoiding the use of aqueousphase sorbents, the amount of heat required for regeneration is greatly reduced, making possible large extraction capacities at sites where process heat is available.

Immobilized amine sorbents [34-37] have been the subject of considerable research because of their promise for applications in natural gas treating and in flue gas carbon capture and storage (CCS), where $\mathrm{CO}_{2}$ concentrations reach $15 \%$. Such amines can also adsorb appreciable amounts of $\mathrm{CO}_{2}$ at ambient atmosphere concentrations and subsequently desorb at temperatures consistent with the use of low-grade process heat $(<120 \mathrm{deg}$. C). For example, immobilized amine sorbents based on aminopropyl functionalities have been shown to adsorb appreciable amounts of $\mathrm{CO}_{2}$ at ambient atmospheric concentrations and temperatures, with near full release of sorbed $\mathrm{CO}_{2}$ at 75 deg. $\mathrm{C}$ [36]. We are conducting a comprehensive evaluation of the aziridine-based immobilizarion chemistry described in Ref. 35. Published results and our findings to date from temperature dependence studies [12] indicate practical desorption temperatures consistent with the use of process heat.

In addition to the efficient use of low-grade process heat for sorbent regeneration, an economical high-throughput process design must provide sufficiently large contacting area without incurring unacceptably high costs associated with moving large amounts of air through the sorbent reactor. Another key requirement is the ability to fabricate reactor components using known, readily available materials and manufacturing techniques. The high adsorption capacity and relatively low mass of immobilized amine sorbent systems greatly simplifies the engineering design of such a process. Such designs have been developed in concert with a professional process engineering firm. These designs, along with the fundamental sorbent considerations summarized above, demonstrate the technical feasibility of a TSA process utilizing process heat and the potential for substantially reduced extraction costs.

In the following illustrative example, we assumed that only process heat is employed to power the regeneration process. Such process heat is generated by all thermally-based power plants (fossil-fueled, nuclear fission, solar concentrator, geothermal), as well as energy-intensive manufacturing (e.g., metals refining, petrochemicals). We used an estimated extraction energy efficiency of $2 \mathrm{~kg}-\mathrm{CO}_{2} / \mathrm{kWh}$-electric for available immobilized amine sorbents operating in an extraction facility sited at a standard pulverized coal-burning power plant. This value follows from an analysis of the energy required to power a TSA process with low-grade process heat using amine sorbents and an assumed heat of sorption of $60 \mathrm{~kJ} / \mathrm{mol}$ [12]. The overall process allows an air-extraction facility at such a power plant to extract twice the plant's emitted $\mathrm{CO}_{2}$.

Figure 3 shows a representative emissions profile that achieves a carbon-negative solution based on new air extraction technology. The A1T scenario is used as a reference case. Aggressive operational deployment is assumed to begin in 2015, a date believed achievable given the state of the technology. By 2020 the worldwide deployment rate achieves half the 
projected deployment rate of new primary power generation assets, and emissions begin to decline. From 2020 through 2040, the pace of deployment matches the growth of primary power assets in the A1T scenario, while maintaining the 50 percent installation ratio. After 2040 , there is no further net deployment, and the extraction level of of $34 \mathrm{Gtonne}-\mathrm{CO}_{2} / \mathrm{yr}$ is sustained for the remainder of the century. The worldwide land dedication associated with this extraction level is estimated at less than $300 \mathrm{~km}^{2}$. The total extraction for the century is approximately 2,400 Gtonne- $\mathrm{CO}_{2}$, in line with IPCC estimates for the accessible capacity of geological formations and substantially less than the potential capacity of deep saline formations [38].

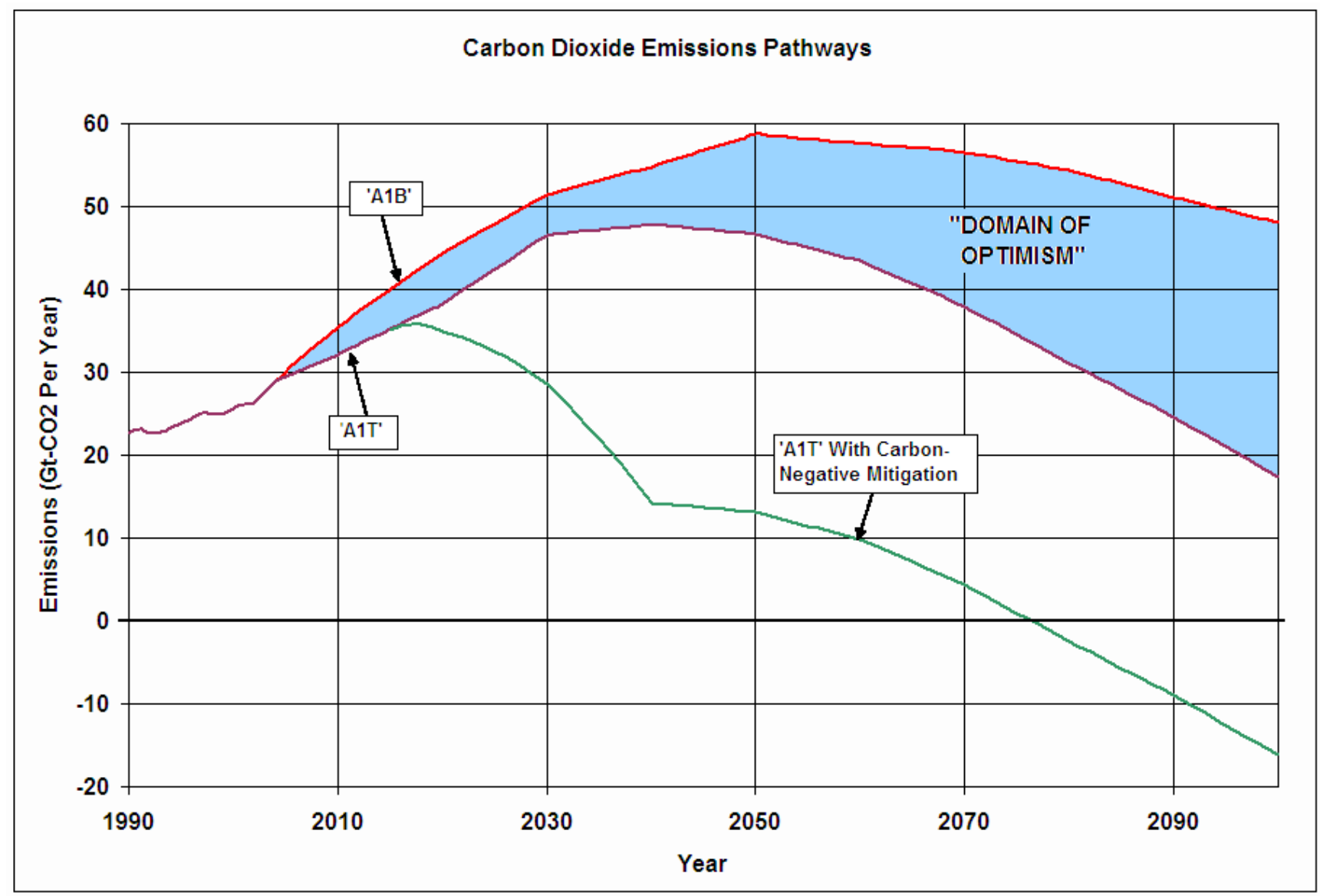

Figure 3. Carbon dioxide emissions pathways of Figure 1 with the addition of a carbon-negative mitigation scenario to A1T, as discussed in the text. Carbon-negative mitigation via air extraction begins in 2015 and reaches $34 \mathrm{Gtonne}-\mathrm{CO}_{2} / \mathrm{yr}$ in 2040. This level is sustained for the remainder of the century. Emissions peak by 2020 and become net negative later in the century as the energy shifts and efficiency gains of scenario A1T take hold.

As shown in the figure, the extraction level eventually offsets not only all power generation emissions but the transportation and industrial/commercial sectors as well. Consequently net $\mathrm{CO}_{2}$ emissions achieve negative values. Offset of these sectors and the realization of negative net emissions cannot be achieved by flue gas CCS alone. Indeed it has been estimated that halving emissions by 2050 , which requires decarbonization of the transportation sector, will need options costing up to $\$ 200 /$ tonne- $\mathrm{CO}_{2}$ [39]. 
Figure 4 shows the effect of air extraction deployment on atmospheric $\mathrm{CO}_{2}$, relative to the optimistic A1T scenario. At the end of the century, the $\mathrm{CO}_{2}$ level has returned to current values and is still declining. This level of atmospheric $\mathrm{CO}_{2}$ is presumed to represent a substantially lower-risk atmosphere. The lowermost curve in the figure shows the cost as a percent of world GDP (PPP basis), assuming a constant and undiscounted extraction-andsequestration cost of $\$ 25 /$ tonne- $\mathrm{CO}_{2}$. This cost is consistent with the developments discussed above and is believed within reach using available sorbents and process hardware [12]. The total undiscounted implementation cost to 2100 is about $\$ 60$ trillion, representing $0.18 \%$ of world GDP. Adapting the 1.5\% time discount rate used by Nordhaus [19] reduces these figures by about half. Lower future extraction costs, which may be achievable with through continuing $R \& D$, can substantially lower the longer term projected economic cost.

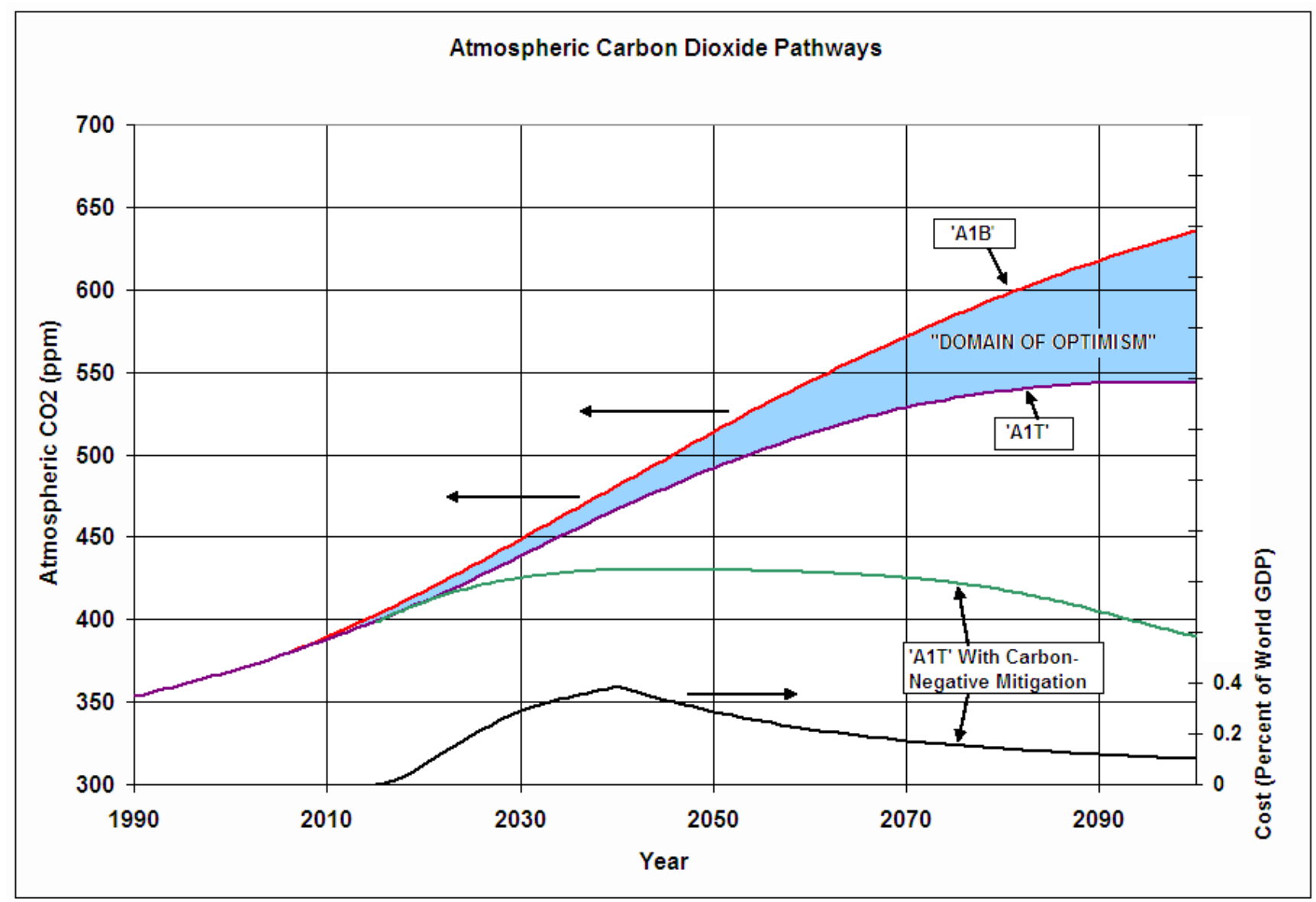

Figure 4. Atmospheric carbon dioxide levels to 2100 corresponding to the emissions scenarios of Figure 3. With the carbon-negative scenario of Figure 3, the atmospheric level peaks at only $10 \%$ above the current level and returns to current levels by century's end. The annual undiscounted cost of carbon-negative mitigation via air extraction, as a percent of world GDP, is shown in the lowermost curve (right hand vertical axis), for a constant unit cost of $\$ 25 /$ tonne- $\mathrm{CO}_{2}$. Adopting the $1.5 \%$ time discount rate used by Nordhaus [19] reduces the total cost over the century by about half.

To achieve the same lower-risk atmosphere results using the less optimistic but still relatively progressive A1B scenario as a reference case requires substantially longer and more extensive air extraction deployment, with correspondingly higher costs. This result 
underscores the importance of a simultaneous, orderly, economically efficient transition to a nearly emissionless energy portfolio by century's end.

\section{Conclusions}

We have shown that extensive deployment of air extraction technology capitalizing on recent scientific developments has the potential to substantially lower the risk of greenhouse gas emissions, while maintaining anticipated global economic growth. This deployment complements an orderly transition to nearly emissionless energy by century's end. Therefore, there exist significant incentives for accelerated R\&D efforts on new air extraction technology. This R\&D should pursue energy cost reductions and define new configurations for siting at energy-generating and other industrial facilities where low-grade process heat can be harvested to power atmospheric extraction.

\section{Acknowlegments}

The authors thank Professor Robert $\mathrm{H}$. Socolow for his critical reading of the manuscript and helpful suggestions. We also wish to acknowledge Carmagen Engineering, Inc. for their contributions to process engineering designs for air capture of $\mathrm{CO}_{2}$ and their valuable critiques and suggestions.

\section{References and Notes}

1. Nakicenovic, N. et al., Special Report on Emissions Scenarios, Intergovernmental Panel on Climate Change, 2000

2. The IPCC has commissioned the development of new scenarios to serve as common starting points for climate and integrated assessment models for a future Fifth Assessment Report. Among these potential new scenarios are emissions profiles reflecting carbon-negative measures taken later in the $21^{\text {st }}$ century, in addition to more familiar mitigation actions taken earlier in the century (e.g., Scenario 'IMAGE 2.6' in Emissions Categories I/II; van Vuuren, D.P. et al., Climatic Change 2007, 81,119). The technical feasibility and robustness of these scenarios has not yet been established by the IPCC, and it is not yet known which will be adopted as a new low pathway scenario. For further information, refer to IPCC-XXVIII/Doc.8 (19.III.2008), Further Work on Scenarios: Report From the IPCC Expert Meeting Towards New Scenarios for Analyses of Emissions, Climate Change, Impacts, and Response Strategies, September 19-21, 2007, Noorwijkerhout, The Netherlands.

3. Pacala, S. and Socolow, R., Stabilization Wedges: Solving the Climate Problem for the Next 50 Years with Current Technology, Science, 2004, 305, 968-972

4. Keith, D.W., Engineering the Planet, in: S. Schneider, A. Rosencranz, and M. Mastrandrea, eds., Climate Change Science and Policy, Island Press, Washington D.C., in press; available at: www.ucalgary.ca/ keith/papers/89.Keith.EngineeringThePlanet.p.pdf

5. Buesseler, K.O., et al., Ocean Iron Fertilization - Moving Forward in a Sea of Uncertainty, Science, 2008, 319, 162 
6. Matthews, H.D. and Caldeira, K., Transient Climate-Carbon Simulations of Planetary Geoengineering, Proc. Nat. Acad. Sciences, 2007, published on line, doi:10.1073/pnas0700419104

7. Kraxner, F., Nilsson, S., and Obersteiner, M., Negative Emissions from BioEnergy Use (BECS) - The Case for Biomass Production by Sustainable Forest Management from Semi-natural Temperate Forests, Biomass and Bioenergy, 2003, 24, 285-296

8. Lackner, K.S., Ziock H.-J., and Grimes, P., Carbon Dioxide Extraction from the Air: Is it an Option?, in: Sakkestad, B., ed., Proceedings of the 24th International Conference on Coal Utilization \& Fuel Systems, Coal Technology Association, Gaithersburg, MD USA, 1999, 885-896

9. Lackner, K.S., Climate Change: A Guide to $\mathrm{CO}_{2}$ Sequestration, Science, 2003, 300, 1677-1678

10. Stolaroff, J.K., Keith, D.W., and Lowry, G.V., Carbon Dioxide Capture from Atmospheric Air Using Sodium Hydroxide Spray, Environmental Science and Technology, 2008, 42, 2728-2735

11. Wright, A.B. and Lackner K.S., Method and Apparatus for Extracting Carbon Dioxide from Air, U.S. Patent Application 20080087165, published 4/17/08; Lackner, K. S., Thermodynamics of the Humidity Swing Driven Air Capture of Carbon Dioxide, to be published

12. Eisenberger, P.M., et al., Process for Air Extraction of $\mathrm{CO}_{2}$ Using Immobilized Adsorbents, to be published

13. Little Green Data Book 2007, International Bank for Reconstruction and Development, The World Bank, Washington DC, 2007

14. Emissions From Fuel Combustion, Vol. 2007 release 01, International Energy Agency, Paris, 2007

15. System for the Analysis of Global Markets, Energy Information Administration, U.S. Department of Energy, Washington DC, 2007

16. The Outlook for Energy: A View to 2030, Exxon Mobil Corporation, Irving TX, 2007

17. Pielke, Jr., R.A., Wigley, T.M.L., and Green, C., Dangerous Assumptions, Nature, 2008, 452, 531-532

18. Roe, G.H. and Baker, M.B., Why Is Climate Sensitivity So Unpredictable?, Science, 2007, 318, 629-632

19. Nordhaus, W., The Challenge of Global Warming: Economic Models and Environmental Policy, July 2007, economics discussion paper, available at http://nordhaus.econ.yale.edu/dice mss 072407 all.pdf

20. Nordhaus, W., A Question of Balance: Weighing the Options on Global Warming Policies, Yale University Press, New Haven CT, 2008

21. Keith, D.W., Ha-Duong, M., and Stolaroff, J.K., Climate Strategy with $\mathrm{CO}_{2}$ Capture from the Air, Climatic Change, 2005, 74, 17-74

22. Pielke, Jr., R. A., 2009 (in press). An Idealized Assessment of the Economics of Air Capture of Carbon Dioxide in Mitigation Policy, Environmental Science \& Policy, 2009 (in press) of carbon dioxide in mitigation policy. Environ. Sci. Policy (2009), doi:10.1016/j.envsci.2009.01.002

23. The story line for the $A 1$ scenarios is available at www.grida.no/climate/ipcc/emission/093.htm\#1

24. The carbon cycle model is an impulse response function representation of the Bern CC model employed in the IPCC-TAR (2001) (F. Joos, University of Bern). Because fossil fuels are not the only source of $\mathrm{CO}_{2}$ emissions, the calculated atmospheric 
concentrations presented here are slightly lower than those published for the various scenarios by the reference Bern $\mathrm{CC}$ model.

25. Hoffert, M.H. et al., Energy Implications of Future Stabilization of Atmospheric $\mathrm{CO}_{2}$ Content, Nature, 1998, 395, 881-884

26. Hoffert, M.H. et al., Advanced Technology Paths to Global Climate Stability: Energy for a Greenhouse Planet, Science, 2002, 298, 981-987

27. Wigley, T.M.L., Richels, R., and Edmonds, J. A., Economic and Environmental Choices in the Stabilization of Atmospheric $\mathrm{CO}_{2}$ Content, Nature, 1996, 240, 240-243

28. GDP Release 03-27-08, Bureau of Economic Analysis, U.S. Department of Commerce, Washington DC, 2007

29. Ausubel, J.H. and Marchetti, C., The Evolution of Transport, The Industrial Physicist, 2001, 7, 20-24

30. Ausubel, J.H., Marchetti, C., and Meyer, P.S., Toward Green Mobility: The Evolution of Transport, European Review, 1998, 6, 143-162

31. Abanades, J.C. et al., Special Report, Carbon Dioxide Capture and Storage, Working Group III of the Intergovernmental Panel on Climate Change, Cambridge University Press, New York, 2005, Chapters 5-7

32. Carbon Sequestration: Carbon Capture, National Energy Technology Laboratory, U.S. Department of Energy, Washington DC, available at http://www.netl.doe.gov/technologies/carbon seq/core $\mathrm{rd} /$ co2capture.html

33. Ref. 31, Chapter 3, Section 3.1.1

34. Gray, M.L. et al., Performance of Immobilized Tertiary Amine Solid Sorbents for the Capture of Carbon Dioxide, Int. J. Greenhouse Gas Control, 2007, 2, 3-8

35. Hicks, J.C. et al., Designing Adsorbents for $\mathrm{CO}_{2}$ Capture from Flue Gas Hyperbranched Aminosilicas Capable of Capturing $\mathrm{CO}_{2}$ Reversibly, J. Am. Chem. Soc., 2008, 130, 2002-2003

36. Huang, H.Y., Yang, R.T., Chinn, D., and Munson, C.L., Amine-grafted MCM-48 and Silica Xerogel as Superior Sorbents for Acidic Gas Removal From Natural Gas, Ind. \& Eng. Chem. Res., 2003, 42, 2427-2433

37. Harlick, P.J.E. and Sayari, A., Applications of Pore-Expanded Mesoporous Silica.5. Triamine Grafted Material With Exceptional $\mathrm{CO}_{2}$ Dynamic and Equilibrium Adsorption Performance, Ind. \& Eng. Chem. Res., 2007, 46, 446-458

38. Ref. 31, Summary for Policy Makers and Chapter 5, Section 5.3.7

39. Energy Technology Perspectives, International Energy Agency, Paris, 2008 